\title{
Analisis Ekonomi Politik Terhadap Korupsi (Dalam Perspektif Struktural Menuju Pemahaman Teoritik Baru Tentang Korupsi Politik Di Indonesia) \\ Muhammad Ali ${ }^{1}$ \\ 1Prodi Administrasi Publik, Universitas Muhammadiyah Mataram , Indonesia
}

\section{INFO ARTIKEL}

\section{Riwayat Artikel:}

Diterima: 10-02-2018

Disetujui: $11-03-2018$

\section{Kata Kunci:}

1. Pemberantasan

2. Korupsi

3. Ekonomi

4. Politik

\section{ABSTRAK}

Abstrak: Korupsi merupakan permasalahan mendesak yang harus diatasi, agar tercapai pertumbuhan ekonomi yang sehat. Berbagai catatan tentang korupsi yang selalu diberitakan oleh media massa baik cetak maupun elektronik, tergambar adanya peningkatan dan pengembangan model-model korupsi. Retorika anti korupsi tidak cukup untuk menyelesaikan/memberhentikan praktek tercela ini. Peraturan perundangundang yang merupakan bagian dari politik hukum yang dibuat oleh pemerintah, menjadi meaning less, apabila tidak dibarengi dengan kesungguhan untuk manifestasi dari peraturan perundang-undangan yang ada. Politik hukum tidak cukup, apabila tidak ada recovery terhadap para eksekutor atau para pelaku hukum. Penelitian ini bertujuan untuk mengetahui bagaimana implikasi ekonomi politik terhadap korupsi di Indonesia, dan strategi apa yang dapat dilakukan untuk meminimalisir praktek korupsi tersebut serta bagaimana multiplier effect bagi efesiensi dan efektifitas pembangunan ekonomi di Indonesia.

Penelitian ini menggunakan metode kualitatif dengan pendekatan deskriptif. Dalam hal ini peneliti mendeskripsikan hasil penelitian. Oleh karena itu peneliti melakukan observasi dan wawancara kemudian menganalisisnya dengan pengumpulan data, reduksi data,display data, dan penarikan kesimpulan.

Hasil penelitian dapat disimpulkan bahwa Pemberantasan korupsi seakan hanya menjadi komoditas politik, bahan retorika ampuh menarik simpati. Oleh sebab itu dibutuhkan kecerdasan masyarakat sipil untuk mengawasi dan membuat keputusan politik mencegah makin mewabahnya penyakit kotor korupsi di Indonesia. Memang tidak memudahkan menghilangkan korupsi tetapi harus diupayakan untuk meminimalisasi korupsi.

\section{Abstract}

Corruption is an urgent issue that must be overcome, in order to achieve healthy economic growth. Various notes on corruption that are always preached by the mass media both print and electronic, illustrated the increase and development of corruption models. Anti-corruption rhetoric is not enough to resolve / dismiss this disgraceful practice. Legislation that is part of the legal politics made by the government, becomes meaning less, if not accompanied by seriousness to manifestation of existing legislation. Legal politics is not enough, if there is no recovery of the executor or the perpetrators of the law.

This study aims to find out how the political economic implications of corruption in Indonesia, and what strategies can be done to minimize corruption practices and how multiplier effect for the efficiency and 

1. Eradication
2. Corruption
3. Economics
4. Politics

\begin{abstract}
effectiveness of economic development in Indonesia.
This research uses qualitative method with descriptive approach. In this case researchers describe the results of research. Therefore, researchers conducted observations and interviews then analyzed it with data collection, data reduction, data display, and conclusions.

The results can be concluded that the eradication of corruption as if only a political commodity, powerful material rhetoric attract sympathy. Therefore, civil society's intelligence is needed to monitor and make political decisions to prevent the corruption of corruption in Indonesia. It is not easy to eliminate corruption but should be sought to minimize corruption.
\end{abstract}

Korupsi merupakan permasalahan mendesak

\section{Latar Belakang}

Paper ini akan mengkaji, bagaimana implikasi ekonomi politik terhadap korupsi di Indonesia, dan strategi apa yang dapat dilakukan untuk meminimalisir praktek korupsi tersebut serta bagaimana multiplier effect bagi efesiensi dan efektifitas pembangunan ekonomi di Indonesia.

Kalau dicermati fenomena pemberantasan korupsi menjadi hal yang selalu diperbincangkan berbagai kalangan, juga terdengar dalam teks pidato para pejabat Negara. Demikian juga masyarakat melalui Lembaga Swadaya Masyarakat (LSM) dan Organisasi kemasyarakatan (Ormas) pun selalu membicarakan persoalan korupsi di Indonesia. Pembahasan mengenai strategi pemberantasan korupsi dilakakukan dibanyak ruang seminar, booming anti korupsi. Meanstream perlawanan terhadap korupsi juga dijewantahkan melalui pembentukan lembaga Adhoc, Komisi Anti Korupsi (KPK). Peraturan perundang-undangan (legislation) yang merupakan wujud dari politik hukum institusi Negara, dirancang dan disahkan sebagai undangundang pemberantasan tindak pidana korupsi. Secara parsial, dapat dikatakan pemerintah serius melawan dan memberantas tindak pidana korupsi di negeri ini.

Beberapa pendapat baik praktisi maupun pengamat hukum terhadap gerak pemerintah dalam menangani kasus korupsi akhir-akhir ini, dimana kelemahan hukum selalu menjadi senjata ampuh para pelaku korupsi untuk menghindar dari tuntutan hukum. Kasus Korupsi baik di era orde baru maupun reformasi tidak memperoleh titik penyelesaian. Perspektif politik selalu mendominasi kasus-kasus hukum di negeri ini. Padahal penyelesaiaan kasus-kasus korupsi besar seperti kasus korupsi Soeharto dan kroninya, dana BLBI dan kasus-kasus korupsi besar lainnya akan mampu menstimulus program pembangunan ekonomi di Indonesia. yang harus diatasi, agar tercapai pertumbuhan ekonomi yang sehat. Berbagai catatan tentang korupsi yang selalu diberitakan oleh media massa baik cetak maupun elektronik, tergambar adanya peningkatan dan pengembangan model-model korupsi. Retorika anti korupsi tidak cukup untuk menyelesaikan/memberhentikan praktek tercela ini. Peraturan perundang-undang yang merupakan bagian dari politik hukum yang dibuat oleh pemerintah, menjadi meaning less, apabila tidak dibarengi dengan kesungguhan untuk manifestasi dari peraturan perundang-undangan yang ada. Politik hukum tidak cukup, apabila tidak ada recovery terhadap para eksekutor atau para pelaku hukum.

Konstelasi seperti ini mempertegas alasan dari politik hukum yang dirancang oleh pemerintah tidak lebih hanya sekedar memenuhi meanstream yang sedang terjadi. Dimensi politik hukum yang merupakan "kebijakan pemberlakuan" atau "enactment policy", merupakan kebijakan pemberlakuan sangat dominan di Negara berkembang, dimana peraturan perundangundangan kerap dijadikan instrumen politik oleh pemerintah, penguasa untuk hal yang bersifat negatif atau positif. Dan konsep perundangundangan dengan dimensi seperti ini dominan terjadi di Indonesia, yang justru membuka pintu bagi masuknya praktek korupsi melalui kelemahan perundang-undangan. Kondisi ini bisa diamati pada Undang-undang bidang ekonomi. Hal positif yang dicermati dari UU, oleh pemerintah adalah dalam rangka memajukan kehidupan politik warga Negara, memperbaiki perekonomian dan lain sebagainya.

Sementara yang bersifat negatif terjadi banyak di Negara berkembang yang menganut pemerintahan otoriter atau diktatorial. UU dengan konsep ini dijadikan semacam legitimasi bagi kekuasaan yang memunculkan istilah Rule by Law dalam pengertian negatif dan bukan Rule of Law. 
Bebrapa regulasi yang terkait dengan fenomena ekonomi seperti Undang-undang Perseroan Terbatas, Undang-undang Pasar Modal, Undangundang Hak Tanggungan, UU Dokumen Perusahaan, UU Kepailitan, UU Perbankan, UU Persaingan Usaha, UU Perlindungan Konsumen, UU Jasa Konstruksi, UU Bank Indonesia, UU Lalu Lintas Devisa, UU Arbitrase, UU Telekomunikasi, UU Fidusia, UU Rahasia Dagang, UU Desain Industri dan banyak UU bidang ekonomi lainnya. Hampir semua peraturan perundang-undangan tersebut memiliki dimensi kebijakan politik hukum, yaitu "kebijakan pemberlakuan", dan memberikan ruang terhadap terjadinya praktek korupsi.

Fakta yang terjadi menunjukkan bahwa Negara-negara industri tidak dapat lagi mempengaruhi/menggurui Negara-negara berkembang terkait praktik korupsi, karena melalui korupsilah sistem ekonomi-sosial rusak, baik Negara maju dan berkembang. Bahkan kalau dicermati bahwa peran besar Negara adidaya seperti Amerika Serikat melalui lembaga donor seperti IMF, Bank Dunia dan perusahaan multinasional menjerat Negara berkembang seperti Indonesia dalam kubangan korupsi yang merajalela dan terperangkap dalam hutang luar negeri, seluruhnya dikorupsi oleh penguasa Indonesia saat itu. Hal ini dilakukan dalam upaya hegemoni terhadap pembangunan ekonomi di Indonesia.

\section{Tinjauan Pustaka}

Jeremy Pope (2000) dalam bukunya Confronting Coruption: The Element of National Integrity System, menjelaskan bahwa korupsi merupakan permasalahan global yang harus menjadi keprihatinan semua orang. Praktik korupsi biasanya sejajar dengan konsep pemerintahan totaliter, diktator yang meletakkan kekuasaan di tangan segelintir orang. Namun, tidak berarti dalam sistem sosial politik yang demokratis tidak ada korupsi bahkan praktek korupsinya selalu meningkat, apabila kehidupan sosial-politiknya toleransi bahkan memberikan ruang terhadap praktek korupsi. Korupsi juga sebagai tindakan pelanggaran hak asasi manusia, dan merupakan tindakan memperbesar biaya untuk barang dan jasa, memperbesar utang suatu Negara, dan menurunkan standar kualitas suatu barang. Biasanya proyek pembangunan dipilih karena alasan keterlibatan modal besar, bukan pada urgensi kepentingan publik. Korupsi selalu menyebabkan situasi sosialekonomi tidak pasti (uncertenly).

Ketidakpastian ini tidak menguntungkan bagi pertumbuhan ekonomi dan peluang bisnis yang sehat. Selalu terjadi asimetris informasi dalam kegiatan ekonomi dan bisnis. Sektor swasta sering melihat ini sebagai resiko terbesar yang harus ditanggung dalam menjalankan bisnis, sulit diprediksi berapa Return of Investment (ROI) yang dapat diperoleh karena biaya yang harus dikeluarkan akibat praktek korupsi juga sulit diprediksi. Akhiar Salmi (2006) menjelaskan bahwa korupsi merupakan perbuatan buruk, seperti penggelapan uang, penerimaan uang sogok dan sebagainya. Selanjutnya dijelaskan makna korupsi sebagai" An act done with an intent to give some advantage inconsistent with official duty and the right of others. The act of an official or fiduciary person who unlawfully and wrongfully uses his station or character to procure some benefit for himself or for another person, contrary to duty and the right of others."

Undang-undang Republik Indonesia Nomor 28 Tahun 1999 tentang Penyelenggaraan Negara yang Bersih dan Bebas dari Korupsi, Kolusi dan Nepotisme, pasal 1 menjelaskan bahwa tindak pidana korupsi sebagaimana maksud dalam ketentuan peraturan perundang-undangan yang mengatur tentang tindak pidana korupsi. Jadi perundang-undangan Republik Indonesia mendefenisikan korupsi sebagai salah satu tindak pidana. Mubaryanto (2004), penggiat ekonomi Pancasila, menjelaskan tentang korupsi bahwa salah satu masalah besar berkaitan dengan keadilan adalah korupsi, yang kini dilunakkan menjadi "KKN". Perubahan nama dari korupsi menjadi KKN ini beralasan karena praktek korupsi memang terkait koneksi dan nepotisme. Tetapi tidak dapat dipungkiri bahwa dampak "penggantian" ini tidak baik karena KKN ternyata dengan kata tersebut praktek korupsi lebih mudah ditoleransi. Dengan penggunaan kata korupsi secara gamblang dan jelas, tanpa tambahan kolusi dan nepotisme.

Korupsi, adalah salah satu masalah yang dihadapi oleh bangsa Indonesia. Sejak 1998, masalah yang tidak pernah tuntas adalah pemberantasan korupsi, kolusi, dan nepotisme. Indonesia memang memiliki Komisi Pemberantasan Korupsi, (KPK) sebuah lembaga negara yang 'khusus' dibuat untuk menyelesaikan masalah korupsi yang dibentuk pada tahun 2002, tetapi tren korupsi masih saja terjadi di Indonesia selama satu dekade terakhir. Pertanyaan yang selalu dikedepankan kalangan akademisi maupun aktivis anti-korupsi, mengapa fenomena korupsi hingga saat ini belum dapat diselesaikan oleh pemerintah? Apa solusi yang tepat guna mengatasi masalah ini? Tren yang terjadi dari tahun ke tahun, praktik politik Indonesia semakin mengarah pada perilaku koruptif, hingga menyeret tidak hanya aparatur birokrasi, tetapi juga polisi, politikus hingga aktor 
yudisial. Akibatnya, korupsi kini menjadi seperti 'kanker' yang tidak kunjung dapat dikeluarkan dari tubuh negara kesatuan Republik Indonesia (Hadiz, 2001; King, 2000).

Ada beberapa argumen yang menjelaskan tentang penyebab korupsi. Paper ini hanya akan mengulas dua pendekatan dalam memahami fenomena korupsi-politik, yaitu perspektif neoliberal dan strukturalis ekonomi-politik.

Mainstream dari kajian korupsi politik pasca-demokratisasi ketiga adalah perspektif neoliberal yang dimotori oleh beberapa lembaga seperti IMF atau World Bank. Perspektif ini percaya bahwa korupsi disebabkan oleh lack of public accountability dalam mengelola urusan-urusan pemerintahan (Tanzi, 1998; Amundsen, 2006; Amundsen, 2009). Dalam perspektif ini, korupsi didefinisikan sebagai the abuse of public power for private benefit, atau yang lebih moderat: the use of public office for private gain (Tanzi, 1998; McNab and Kailey, 2007; The World Bank, 1997; IMF, 1997). Strategi untuk menghadapi korupsi dalam perspektif ini adalah menyerahkan wewenangwewenang publik dari negara kepada masyarakat, baik dengan memperkuat akuntabilitas dan transparansi maupun memperkuat masyarakat sipil (Umar, 2011; Khan, 1998; The World Bank, 2008). Kata kunci yang sering dipakai untuk menjelaskan strategi ini adalah Good Governance, penegakan aparat hukum, atau mekanisme rule of law yang baik (IMF, 1997; Hadiz, 2011;Rinaldi et. al; 2007; Tanzi, 1998).

Paper ini ingin menggunakan pendekatan yang sedikit berbeda dari analisa di atas. Dalam perspektif struktural yang menggunakan analisa pendekatan ekonomi-politik, korupsi dalam konteks 'private gain of public expense' terjadi karena adanya negara yang menjadi instrumen, atau bersifat 'otonom' secara relatif dari kepentingan kelas-kelas dominan (Alavi, 1972; Wright, 1982; Mayer, 1993, Miliband, 1969; Walsh, 2012; Hadiz dan Robison, 2004). Artinya, korupsi merupakan ekses dari negara kapitalis yang melakukan akumukasi kapital, baik untuk kepentingan kelasdominan maupun untuk kepentingan dirinyasendiri, dengan menggunakan struktur pemerintahan secara oligarkis, (Hadiz, 2001; Hadiz dan Robison, 2004, Aditjondro, 2006). Dengan demikian, dapat dipahami bahwa korupsi adalah bentuk kontradiksi-internal dari kapitalisme (Suryajaya, 2012), dan oleh sebab itu harus dilawan dengan melihat akar masalahnya, yaitu relasi politik yang kapitalistik. Kata kunci yang bisa digunakan untuk menjelaskan strategi ini adalah oligarki, negara kapitalis, atau state-captured corruption (Hadiz, 2004; Hadiz, 2005; Rais, 2008; Walsh, 2012, Sullivan, 2010).

Paper ini akan mencermatinya dari pendekatan kedua. Dalam konteks Anti-Corruption Prospect Index, perlu ada analisa mengenai penjelasan ekonomi-politik atas tindak pidana korupsi. Argumennya, korupsi bukan hanya persoalan 'the abuse of public power for private benefit saja, yang mana penyelesaiannya mengandaikan adanya supremasi, tetapi juga harus dilihat dari prakondisi material yang kemudian memungkinkan korupsi itu terjadi. Artinya, penegakan supremasi hukum saja tidak cukup untuk melawan korupsi, tetapi juga perlu 'perlawanan' yang lebih luas untuk memerangi kondisi material yang memungkinkan dan menyebabkan terjadinya korupsi.

\section{Metode Penelitian}

Penelitian ini adalah penelitian kualitatif dengan pendekatan deskriptif. Penelitian kualitatif adalah penelitian yang bermaksud untuk memahami fenomena tentang apa yang dialami oleh subjek penelitian secara holistik, dan dengan cara deskripsi dalam bentuk katakata dan bahasa pada suatu konteks khusus yang alamiah dan dengan memanfaatkan berbagai metode alamiah (Moleong, 2011:6).

\section{Hasil dan Pembahasan}

\section{a. Implikasi ekonomi politik terhadap korupsi}

Dalam studinya tentang korupsi di Cina, Yuliantoro (2012) berargumen bahwa korupsikorupsi politik yang terjadi di Cina sedikit banyaknya lahir dari proses reformasi ekonomi yang dimulai sejak kepemimpinan Deng Xiaoping. Dengan membuka keran kebebasan berusaha bagi pengusaha Cina dan menyediakan iklim investasi. Adanya kebebasan berusaha setelah bertahun-tahun di bawah komunisme menyebabkan adanya 'efeksamping' dari proses reformasi ekonomi, yaitu korupsi. Oleh sebab itu, penting untuk diketahui relasi-relasi ekonomi politik yang terjadi di Indonesia. Paper ini mencoba melihat satu jenis kasus korupsi.

Pada bagian ini, akan ada dua variabel yang diulas. Pertama, korupsi sebagai akumulasi-kapital, persoalan paling serius dan bermasalah dari kapitalisme. Kedua, korupsi sebagai resultante dari oligarki dan state capture, formasi awal dari terbentuknya negara kapitalis yang merupakan 
instrumen dari kelas dominan untuk berkuasa (Miliband, 1969, Alavi, 1972).

\section{b. Akumulasi Kapital dan Demokrasi Liberal}

Salah satu instrument penting dari proses pemberantasan korupsi di Indonesia adalah adanya private gain. Beberapa kasus, seperti Hambalang yang melibatkan Muhammad Nazaruddin, Bendahara Umum Partai Demokrat, terlihat jelas bahwa motif yang melatarbelakangi kasus tersebut adalah akumulasi kapital dalam tajuk 'pembiayaan politik' (lihat Tempo, 2012a; Tempo, 2012b; Tribunnews, 2012). Demokrasi liberal di Indonesia masih terserimpung oleh praktik-praktik klientelisme (Robison, 1986; McIntyre, 2003). Di sini, Politisi (pemangku kepentingan publik) memerlukan 'biaya' untuk meluluskan keiginan politiknya, yang hanya bisa disediakan oleh pengusaha. In return, pengusaha mendapatkan 'kompensasi' berupa proyek-proyek anggaran yang dikuasai melalui patron politisi tersebut. Hal ini yang terjadi dalam kasus Hambalang, di mana posisi politik seorang Nazaruddin memudahkan para pengusaha korup untuk mengakumulasi kapital untuk tujuan politik, akibatnya, terjadi korupsi.

Pada titik ini, "korupsi" dipandang bukan sekadar sebagai pelangggaran hukum, tetapi sebagai bagian dari akumulasi kapital. Dalam perspektif Marxian, korupsi dipandang sebagai 'wajah jelek dari demokrasi yang belum usai" (ugly face of unfinished democracy". Dikatakan belum usai karena demokrasi melahirkan kebebasan yang tidak diimbangi oleh pembudayaan demokrasi sebagai sebuah proses kultural. Akibatnya, demokrasi liberal membuat kebebasan tanpa batas, melahirkan praktik korupsi. (Sullivan, 2002). Artinya, korupsi adalah simbol kegagalan demokrasi (the failure of democracy). Mengapa demokrasi dikatakan gagal? Sebab demokrasi hanya melahirkan proses-proses klientelistik dan oligarki antara kelas kapitalis dan negara. Negara hanya menjadi instrumen dari kelas berkuasa untuk berkuasa dan mengakumulasi kapitalnya dengan jalan politik.

Dalam logika Marxian, akumulasi kapital adalah keuntungan kunci dari kapitalisme (Marx, 1887). Logika kapitalisme mensyaratkan adanya sirkulasi (rumus: M-C-M1). M1 adalah capital yang diakumulasikan. Agar capital dapat diakumulasikan, uang harus diubah dulu menjadi komoditas. Rumusan ini dapat dioperasikan juga pada ranah politik. Agar sebuah komoditas (politik) bisa diubah menjadi kapital (m1), perlu ada biaya (m). Biaya tersebut diakumulasikan untuk menjadi komoditas. Proses transformasi dari komoditas menjadi kapital itulah, pada ranah politik, yang kemudian menyebabkan korupsi. Mengapa hal ini bisa terjadi? Penjelasan sederhananya: politik dibatasi oleh 'hukum', sebab sumber daya yang memungkinkannya untuk melakukan akumulasi tersebut adalah milik negara (dalam konteks industri yang digambarkan oleh Marx, aktivitas akumulasikapital tersebut beroperasi dalam eksploitasi kerja buruh).

Oleh sebab itu, seorang politisi harus mencari pembiayaan dengan melakukan aktivitas 'di-luar-hukum' dengan membajak kekayaan negara melalui kekuasaan politiknya. Dalam logika Marxian, akar masalahnya jelas bukan pelanggaran hukumnya, tetapi akumulasi kapital yang embedded dengan proses demokrasi liberal (politik biayatinggi). Akumulasi kapital inilah yang memungkinkan korupsi terjadi, karena penguasaan sektor publik untuk mengumpulkan kapital hanya mungkin dilakukan diluar-hukum, atas kepentingan yang bersifat ekonomis-politis. Inilah yang terjadi dalam kasus pengadaan proyek bermasalah Hambalang yang melibatkan Angelina Sondakh dan Nazaruddin, yang diikuti oleh pihak-pihak lain.

\section{c. Oligarki dan Restorasi Kepentingan Kelas Dominan}

Term Oligarki diperkenalkan untuk melihat penguasaan sumber daya publik oleh segelintir elit dengan relasi klientelistik (Robison, 1986; Hadiz dan Robison, 2004; McIntyre, 2003; Guniev dan Sonin, 2007). Oligarki terjadi ketika ada sifat sukasama-suka antara penguasa dan pengusaha, sehingga aturan yang dibuat oleh penguasa, juga keuntungan yang diberikan oleh pengusaha, diberikan oleh masing-masing pihak. Motif dari korupsi politik adalah mempertahankan eksistensi kekuasaan. Dalam kasus Hambalang, Anas Urbaningrum memerlukan financial backup untuk membiayai aktivitas politiknya di partai demokrat, sehinga dengan demikian ia dapat memastikan kursi kekuasaan sekaligus mempreservasi kekuasaannya (Tempo, 2012a). Financial Backup itu dilakukan dengan dua hal: Pertama, mencari pengusaha yang bisa memberikan kepastian biaya terhadapnya. Kedua, bermain dalam proyek di kementerian yang dikuasai oleh partainya. Ketiga, dengan bermodal jejaring yang ada, ia dapat menguasai sumber dana yang ada pada struktur negara.

Inilah yang disebut dengan oligarki: Ketika struktur negara dikuasai oleh satu atau dua kepentingan dan membuat kesempatan orang lain untuk mengakses sumber daya tersebut terhambat. Oligarki lahir dari struktur politik yang klientelistik. Struktur politik yang berciri patron-klien tersebut ditandai oleh adanya simbiosis mutualisme antara politisi dengan pemilik modal. Motifnya, politisi 
memerlukan modal untuk biaya politiknya, sementara pengusaha memerlukan dukungan politik untuk eksistensi usahanya. Akibatnya, ada hubungan yang koruptif di level pemerintah. Dalam perspektif ekonomi-politik, oligarki melahirkan private gain: adanya bagian yang besar yang didapatkan oleh politisi dari pengusaha membuat uang negara masuk ke 'kantong' pengusaha dan 'politisi'. Di kasus Anas Urbaningrum, hal ini terlihat dari upayanya menggunakan proyek anggaran untuk memenangi kursi Ketua Umum Partai Demokrat -sebuah abuse of public power for private benefit.

Bagaimana oligarki beroperasi sebagai korupsi? Ada sebuah istilah yang kemudian berkembang, terutama dalam konteks Indonesia pasca-Orde Baru: State-Captured Corruption. Hadiz dan Robison (2004) menjelaskan bahwa pasca-Orde Baru, terjadi fenomena rekonstitusi oligarki yang beroperasi melalui 'kembalinya' elitelit ekonomi dan politik lama yang terlibat dalam tiang pancang fondasi rezim Soeharto. Mereka kembali menemukan posisinya sebagai elit-elit bisnis dan politisi. Bedanya, di era ini, politisi dan pebisnis korup tersebut melakukan aktivitasnya tidak melalui struktur birokrasi negara seperti zaman Orde Baru, melainkan jalur politik parlementer.

Akibatnya, struktur politik parlementerian dipenuhi oleh berbagai anomali: korupsi yang terjadi melibatkan banyak aktor dan banyak sektor. Pengusaha menggunakan struktur politik untuk mendesain kebijakan, aturan hukum, serta aturan main dalam berbagai kompetisi bisnis atau politik yang menguntungkan dirinya dan memungkinkannya melakukan akumulasi kapital (Matei, 2009). Inilah yang disebut dengan statecaptured corruption yang muaranya adalah restorasi kepentingan kelas dominan.

Dalam kasus Hambalang, kita bisa melihat modus paling kuat dari state captured corruption ini. Korupsi beroperasi melalui digunakannya struktur negara (proyek Hambalang) oleh politisi korup untuk kepentingan pribadinya. Seluruh desain, aturan main, hingga proses permainan dimainkan oleh kekuatan politik yang berorientasi pada akumulasi kapital. Sudah barang tentu, diperlukan "orang dalam" dari Kementerian yang bersangkutan untuk menyukseskan proyek korupsi tersebut. Pada titik inilah, struktur negara (kementerian Pemuda dan Olahraga) dibajak oleh kepentingan pemilik modal yang berkolaborasi dengan politisi untuk menyukseskan kepentingan diri-sendiri.

\section{d. Korupsi dan The Capitalist State: Sebuah Kesimpulan.}

Penelusuran kasus Hambalang dengan menggunakan analisa ekonomi-politik tersebut melahirkan sebuah kesimpulan: korupsi adalah bagian utama dari trayektori "negara kapitalis". Jika menggunakan trayektori yang dikembangkan oleh Marx sampai ke Miliband, kendati diproblematisir oleh Poulantzas, "negara kapitalis" adalah instrumen dan representasi kekuasaan dari kelas borjuasi/kelas dominan. Lahirnya korupsi dalam sebuah dinamika politik, dalam perspektif ekonomipolitik, adalah bentuk formatif dari negara kapitalis. Ia beroperasi melalui akumulasi-kapital dan formasi oligarki yang kemudian membajak struktur negara untuk kepentingan pribadi (the abuse of public power for private benefit).

Hanya saja, muncul pertanyaan: jika korupsi adalah sebuah bentuk formatif dari "negara kapitalis", mengapa pendekatan neoliberal yang juga pro pada kapitalisme justru mengampanyekan untuk melawan korupsi di negara-negara dunia ketiga? Jawabannya, menurut kami, adalah sifat dari korupsi yang melawan-hukum. "Hukum" meminjam Foucault — adalah instrumen lain dari negara kapitalis untuk mengoperasikan disciplinary power dan governmentality power kepada masyarakatnya (Nadesan, 2007). Logika kapitalisme primitif telah berevolusi menjadi kapitalisme neoliberal yang beroperasi tidak hanya pada ranah "negara" namun juga "masyarakat".

Oleh sebab itu, dengan menggunakan konsep governmentality Foucault, masyarakat perlu diperkuat untuk melawan korupsi agar bisa diinjeksikan dengan logika kapitalisme pasar. Caranya adalah menghidupkan partisipasi dan akuntabilitas public. Logika perlawanan korupsi dalam pendekatan neoliberal sama-sekali tidak menyasar ke arah akumulasi kapital, sebagaimana dianut oleh kaum Marxis, karena memang perlawanan terhadap korupsi primitif adalah jalanlain dari akumulasi kapital dalam bentuknya yang lebih baik.

Hal yang menjadi kekhawatiran adalah akan terjadi, setelah masyarakat diinjeksi oleh logika anti-korupsi untuk menyukseskan proyek kepentingan pasar, korupsi lahir justru dari institusi pasar itu sendiri, bukan sebagai sesuatu yang melawan-hukum, tetapi sebagai sesuatu yang menindas kepentingan masyarakat yang tidak memiliki modal dan akses terhadap pasar. 
Fenomena ini bisa melanda Negara ini di masa yang akan datang.

\section{Simpulan}

Merangkai kata untuk perubahan memang mudah. Namun, melaksanakan rangkaian kata dalam bentuk gerakan terkadang teramat sulit. Dibutuhkan kecerdasan dan keberanian untuk mendobrak dan merobohkan pilar-pilar korupsi yang menjadi penghambat utama lambatnya pembangunan ekonomi di Indonesia. Korupsi yang telah terlalu lama menjadi wabah yang tidak pernah dituntaskan, karena pembunuhan terhadap wabah tersebut tidak pernah tepat sasaran ibarat "yang sakit kepala, kok yang diobati tangan “.

Pemberantasan korupsi seakan hanya menjadi komoditas politik, bahan retorika ampuh menarik simpati. Oleh sebab itu dibutuhkan kecerdasan masyarakat sipil untuk mengawasi dan membuat keputusan politik mencegah makin mewabahnya penyakit kotor korupsi di Indonesia. Memang tidak memudahkan menghilangkan korupsi tetapi harus diupayakan untuk meminimalisasi korupsi.

\section{Saran}

Pemerintah Republik Indonesia harus menegakkan hukum pada pelaku korupsi di Indonesia agar tidak mewabahnya tindakan korupsi. Perbaikan etika pejabat perlu dilakukan dengan memberikan pendidikan moral yang berkelanjutan sehingga kegiatan korupsi di minimalisir tindakan koropsi di Indonesia.

\section{Daftar pustaka}

[1] Aditjondro, George J. Korupsi Kepresidenan: Reproduksi Oligarki Berkaki Tiga Istana, Tangsi, dan Partai Penguasa (Yogyakarta: LKIS, 2006).

[2] Alavi, Hamza. The Capitalist State in Post-Colonial Societies: Pakistan and Bangladesh. New Left Review no. 69, 1972.

[3] Akhiar Salmi, Paper 2006, "Memahami UU tentang Pemberantasan Tindak Pidana Korupsi", MPKP, FE,UI.

[4] Amundsen, Inge. Political Corruption: An Introduction to the Issues (Bergen: Chr. Michelsen Institute, 1999).

[5] . Political Corruption (Bergen: Chr. Michelsen Insitute, 2006).

[6] Guniev, Sergei dan Konstantin Sonin. Dictators and Oligarchs: A Dynamic Theory of Contested Property Rights. Paper presented at ISNIE Conference (http://ssrn.com/abstract=983908).

[7] Hadiz, Vedi R. "The State of Corruption: Indonesia" dalam Vinay Bhargava dan Emil
Bolongaita. Challenging Corruption in Asia: Case Studies and a Framework for Action (Washington: The World Bank, 2004).

[8] . Dinamika Kekuasaan: Ekonomi Politik Indonesia Pasca Soeharto (Jakarta: LP3ES, 2005).

[9] Jeremy Pope," (2000), Confronting Corruption: The Element of National Integrity System", Transparency International.

[10] Khan, Mushtaq A. "The Role of Civil Society and Patron-Client Networks in the Analysis of Corruption" in Corruption and Integrity Improvement Initiatives in Developing Countries (New Yorkl:UNPD, 1998).

[11] Marx, Karl. The Capital: Critique on Political Economy. Marxist Internet Archive. http://www.marxists.org/

[12] Matei, Andrea. State Capture versus Administrative Corruption: Comparative Study for the Public Health Service in Romania. 2007.

[13] Mayer, Andrew. Marx, Lenin, and Corruption of the Working Class. Political Studies, 1993.

[14] McIntyre, Andrew. Institutions and the Political Economy of Corruption in Developing Countries. Discussion Paper, Workshop on Corruption (Stanford: Stanford University Press, 2003).

[15] McNab, Robert dan Kathleen Bailey. Manuscript 2: Defining Corruption.

[16] Miliband, Ralph. The Capitalist State: A Reply to Poulantzas (New Left Review, 1969).

[17] Mubaryanto, Artikel, “ Keberpihakan dan Keadilan", Jurnal Ekonomi Rakyat, UGM, 2004

[18] Nadesan, Najia Holmer. Governmentality, Biopower, and Everyday Life. (London: Routledge, 2008).

[19] Rais, Amien. Agenda-Mendesak Bangsa: Selamatkan Indonesia! (Yogyakarta: PPSK Press, 2008).

[20] Robert A Simanjutak," (2003), Implementasi Desentralisasi Fiskal:Problema, Prospek, dan Kebijakan", LPEM UI.

[21] Rinaldi, Taufik et. al. Memerangi Korupsi di Indonesia yang Terdesentralisasi (Jakarta: Justice for Poor, The World Bank, 2007.

[22] Richard Robison. Indonesia: The Rise of Capital (New York: Equinox, 1986).

[23] ___ dan Vedi Hadiz. Reorganising Power in Indonesia: The Politics of Oligarchy in an Age of Markets (London: Routledge, 2004)

[24] Sullivan, Stefan. Marx for a Post-Communist Era in Poverty, Corruption, and Banality (London: Routledge, 2002).

[25] Suryajaya, Martin. Materialisme Dialektis: Kajian Marxisme dan Filsafat Kontemporer (Yogyakarta: LKiS, 2012).

[26] Sudjijono, Budi.2008. Resesi Dunia dan Ekonomi Indonesia.Jakarta: Golden Terayon Press.

[27] The World Bank. Helping Countries Combat Corruption: The Role of World Bank (Poverty 
Reduction and Economic Management, The World Bank, 1997).

[28] Tanzi, Vito. Corruption Around the World: Causes, Consequences, Scope and Cures. (IMF Staff Papers, 1998).

[29] Umar, Ahmad Rizky Mardhatillah. Memerangi Korupsi, Memperkuat Partisipasi. Jawa Pos, 4 April 2011.

[30] Undang-undang Republik Indonesia Nomor 32 Tahun 2004 tentang Pemerintah Daerah.

[31] Undang-undang Republik Indonesia Nomor 33 Tahun 2004 tentang Perimbangan Keuangan Pusat dan Daerah.

[32] Wright, Erik Olin. Reading Guide to Political Power and Social Classes by Nicos Poulantzas (University of Wisconsin, 1982, revised). 